\title{
Role of breast tumour kinase in the in vitro differentiation of HaCaT cells
}

\author{
T.C. Wang, ${ }^{\star} \dagger$ S.H. Jee, ${ }^{\star}$ T.F. Tsai, ${ }^{\star}$ Y.L. Huang, ${ }^{\star}$ W.L. Tsai* and R.H. Chen \\ *Department of Dermatology, College of Medicine, National Taiwan University and National Taiwan University Hospital, Taipei, Taiwan \\ $\dagger$ Department of Dermatology, West Garden Hospital and Mackay Memorial Hospital, Taipei, Taiwan \\ †Institute of Molecular Medicine, College of Medicine, National Taiwan University, Taipei, Taiwan
}

\section{Summary}

\section{Correspondence}

Ruey-Hwa Chen.

E-mail: rhchen@ha.mc.ntu.edu.tw

\section{Accepted for publication \\ 1 January 2005}

\section{Key words:}

breast tumour kinase, HaCaT cells, keratinocyte differentiation

\section{Conflicts of interest:}

None declared.
Background Breast tumour kinase (BRK) is a newly identified non-receptor protein tyrosine kinase from a metastatic breast tumour. Its biological functions are still under extensive investigation. The mouse homologue Sik (Src-related intestinal kinase) has been implicated in mouse keratinocyte differentiation; however, not much is known about the functions of BRK in human cutaneous biology.

Objectives Using HaCaT cells as an experimental model, to explore the mutual relationships between BRK and differentiation of human keratinocytes.

Methods Archival paraffin blocks of normal and pathological skin were retrieved for examining the in vivo distribution of BRK. Its expression and subcellular localization were examined via indirect immunofluorescence, and quantitative changes were analysed by Northern and Western blots. The kinase activity of BRK was determined by its autophosphorylation and phosphorylation of exogenous substrate in the in vitro kinase assay. Using a retroviral infection method, we established stably transfected $\mathrm{HaCaT}$ cells expressing vector, wild-type BRK or a kinase-defective mutant (K219M). Expression of the differentiation marker keratin 10 (K10) was compared among these cells using semiquantitative reverse transcription-polymerase chain reaction.

Results Histochemical examination showed that BRK was expressed exclusively in suprabasal keratinocytes. Its distribution was both cytoplasmic and intranuclear. An enhanced regional suprabasal expression pattern was observed in the confluent areas of cell cultures. The expression of BRK transcript and protein was up-regulated in prolonged confluence culture in a serum-dependent manner. Its kinase activity was activated shortly after the addition of calcium and ionomycin and returned to the basal level within $30 \mathrm{~min}$. Overexpression of wild-type BRK moderately promoted the expression of K10 transcript while the kinase-defective BRK mutant exerted a prominent suppressive effect.

Conclusions The in vivo distribution of BRK and its up-regulation during in vitro differentiation of $\mathrm{HaCaT}$ cells, together with the activation of its kinase activity by calcium/ionomycin and its influence on K10 expression, all indicate a role for BRK in the complex process of keratinocyte differentiation.
The human skin forms an essential barrier between the human body and the environment, and is crucial in resisting external insults such as extreme temperature or invasion of pathogens. Keratinocytes, the major constitutive cells, must undergo a finely tuned process of proliferation and differentiation to maintain the integrity of skin. It is known that tyrosine phosphorylation occurs as an early and specific event during keratinocyte differentiation. ${ }^{1}$ Treatment of keratinocytes with inhibitors to specific tyrosine kinase leads to a decrease in the expression of early (keratin 10, K10) and late (involucrin) differentiation markers, and to failure to undergo differentiation. ${ }^{2}$ Fyn-defective keratinocytes show impaired stratification, are much larger in size and express fewer differentiation markers than wild-type cells. ${ }^{3}$ Tyrosine kinase activation also controls cell adherens junction formation, a crucial step for keratinocyte differentiation. ${ }^{4}$

Breast tumour kinase (BRK) was isolated via a polymerase chain reaction (PCR)-based differential screening method 
from a human metastatic breast tumour. ${ }^{5}$ The encoded 451 amino acid peptide is composed of $\mathrm{Src}$ homology (SH) 2, SH3 and catalytic domains, resembling the Src family kinases. ${ }^{5}$ BRK transcripts are detected in some breast tumour cell lines and human primary breast tumours, but not in normal breast tissue. ${ }^{5}$ High levels of BRK expression have also been reported in colon tumours ${ }^{6}$ and in certain metastatic melanoma cell lines. ${ }^{7}$ In advanced, poorly differentiated, prostate tumour cells, BRK manifests an altered cellular distribution and kinase activity, thus implying some clinical significence. ${ }^{8}$ These data collectively implicate a role for BRK in tumorigenesis. Consistently, knockdown of BRK expression by RNA interference diminishes the proliferative ability of breast tumour cells. ${ }^{9}$

Sik (Src-related intestinal kinase) is the mouse homologue of BRK and shares about $80 \%$ identity with BRK. ${ }^{10}$ It also displays an epithelial-specific expression pattern and was first detected in the granular layer of the mouse embryo skin at day $15 \cdot 5 .{ }^{10}$ Sik is activated shortly after the addition of calcium to mouse keratinocytes, and is able to bind but not to phosphorylate a $65-\mathrm{kDa}$ Ras-GTPase activating protein. ${ }^{11}$ Overexpression of Sik results in an increase in the synthesis of the late differentiation marker filaggrin in embryonic mouse keratinocytes. ${ }^{11}$

In this study, we explored the mutual relationships between BRK and differentiation of keratinocytes. The immortalized, non-tumorigenic $\mathrm{HaCaT}$ cell line, which exhibits a differentiation profile comparable with that of primary keratinocytes, $^{12,13}$ was used as our experimental model. We demonstrate the differentiation-specific distribution of BRK in vivo and in vitro, and its serum-dependent up-regulation during differentiation of $\mathrm{HaCaT}$ cells. The kinase activity was activated shortly after intracellular calcium influx. Finally, overexpression of wild-type BRK or a kinase-defective mutant in $\mathrm{HaCaT}$ cells, respectively, promoted or suppressed the expression of the early differentiation marker K10.

\section{Materials and methods}

\section{Cell cultures}

Unless specified, all culture media were purchased from Gibco-BRL (Gaithersburg, MD, U.S.A.) and supplemented with $10 \%$ fetal calf serum (FCS). The HaCaT cell line was kindly provided by Dr N.E. Fusenig (German Cancer Research Centre, Heidelberg, Germany). BT-474, MDA-MB-231 and HaCaT cells were maintained in Dulbecco's modified Eagle's medium (DMEM). For low-calcium culture, calcium-free DMEM and $10 \%$ dialysed FCS were prepared. MCF-10 A cells were grown in DMEM/F12 medium supplemented with 5\% horse serum, hydrocortisone $\left(0.5 \mu \mathrm{g} \mathrm{mL}^{-1}\right)$, cholera toxin $\left(0 \cdot 1 \mu \mathrm{g} \mathrm{mL}^{-1}\right)$, insulin $\left(5 \mu \mathrm{g} \mathrm{mL}^{-1}\right)$ and epidermal growth factor (EGF; 0.01 $\left.\mu \mathrm{g} \mathrm{mL}^{-1}\right)$. When necessary, cell numbers were counted under a microscope with a haemocytometer (Hausser Scientific, Horsham, PA, U.S.A.) and their viability was judged with the trypan blue exclusion test.

\section{Measurement of calcium concentration in medium}

Calcium concentration was measured by flame photometry via a Perkin-Elmer atomic absorption spectrometer 3100. One per cent lanthanum (Fixanal ${ }^{\circledR}$; Riedel-de Haen, Seelze, Germany) was added to each sample before measurement to reduce the oxy salts interference during the procedure. The calcium molarity measured in low-calcium DMEM/10\% dialysed FCS was about $0.06 \mathrm{mmol} \mathrm{L}^{-1}$.

\section{Establishment of stable expression cell lines}

HaCaT cells were infected in the presence of polybrene with the amphotropically packaged retroviral vector pBabePuro (carrying the retroviral long-terminal repeat promoter and the puromycin resistance gene) inserted with Myc-tagged fulllength Brk cDNA or a kinase-defective mutant (K219M). ${ }^{14}$ The latter was created via QuickChange ${ }^{\circledR}$ site-directed mutagenesis kit (Stratagene, La Jolla, CA, U.S.A.) according to the manufacturer's suggestions. Cells were selected with puromycin $\left(1 \mu \mathrm{g} \mathrm{mL}^{-1}\right.$; Sigma, St Louis, MO, U.S.A.) for 2 weeks. Western blot was used to confirm the expression of inserted genes.

\section{Tissue histochemical staining}

Archival skin biopsy specimens were deparaffinized and processed in a microwave for antigen epitope retrieval. The rabbit Immunocruze staining system (Santa Cruz Biotech, Santa Cruz, CA, U.S.A.) was used according to the manufacturer's instructions. Briefly, sections were blocked with goat serum, and then incubated with $2 \mu \mathrm{g} \mathrm{mL}^{-1}$ anti-BRK antibody (Santa Cruz Biotech) at $4{ }^{\circ} \mathrm{C}$ overnight. Biotinylated secondary antibody was added, followed by the addition of horseradish peroxidase (HRP)-streptavidin complex. The target protein was visualized by incubation in peroxidase substrate, using 3,3'-diaminobenzidine as chromogen. Haematoxylin and eosin were used for background staining.

\section{Indirect immunofluorescence}

Cells were plated on coverslips precoated with $0 \cdot 1 \%$ polylysine. After reaching the desired culture conditions, the medium was aspirated and the coverslips were washed at room temperature with phosphate-buffered saline (PBS), then fixed and permeabilized with methanol/acetone $1: 1$ at $-20{ }^{\circ} \mathrm{C}$ for 5 min. The coverslips were blocked at $4{ }^{\circ} \mathrm{C}$ overnight with $10 \%$ goat serum, $1 \%$ bovine serum albumin (BSA) in PBS, and then incubated with BRK and/or K10 (monoclonal anticytokeratin 8.60; Sigma-Aldrich, St Louis, MO, U.S.A.) antibodies at a dilution of $1: 100-1: 200$ in 5\% goat serum and $0 \cdot 2 \%$ BSA in PBS at $4{ }^{\circ} \mathrm{C}$ overnight. The staining results were visualized with fluorescein isothiocyanate-conjugated goat antimouse IgG $(1: 1000)$ or Texas red-conjugated goat antirabbit IgG $1: 500$ after appropriate washes with $0 \cdot 2 \%$ BSA in PBS. The cell nuclei were stained with Hoechst 33258 
(1 : 200; Sigma-Aldrich). Cells were mounted and examined under an immunofluorescence microscope (Leica DM DR). Images were captured with a cool $\mathrm{CCD}$ and processed by National Institutes of Health (NIH) Image J software (developed at NIH and available at http://rsb.info.nih.gov/ij).

\section{Northern blot}

Total RNA was extracted from HaCaT cells with Trizol ${ }^{\circledR}$ reagent (Life Technologies, Gaithersburg, MD, U.S.A.) according to the manufacturer's protocol. For RNA resolution, $25 \mu \mathrm{g}$ RNA was loaded on $1 \%$ formaldehyde gel and electrophoresed at $50 \mathrm{~V}$ for $2 \mathrm{~h}$. After capillary transfer in $10 \times$ saline sodium citrate (SSC) overnight and ultraviolet cross-linking (0.12 J), the membrane (Hybond-N; Millipore, Billerica, MA, U.S.A.) was prehybridized in Church buffer [7\% sodium dodecyl sulphate (SDS), $1 \%$ BSA, $10 \mathrm{mmol} \mathrm{L}^{-1}$ ethylenediamine tetraacetic acid (EDTA), $0.4 \mathrm{~mol} \mathrm{~L}{ }^{-1}$ sodium pyrophosphate (NaPPi), $\mathrm{pH} 7 \cdot 2$ ] at $60{ }^{\circ} \mathrm{C}$ for $1 \mathrm{~h}$ and then hybridized overnight at $60{ }^{\circ} \mathrm{C}$ with $32 \mathrm{P}$-labelled, randomly primed BRK or glyceraldehyde-3-phosphate cDNA probe generated by Rediprime II kit (Amersham Pharmacia, Little Chalfont, U.K.). The hybridized membrane was washed with $2 \times \mathrm{SSC} / 1 \%$ SDS buffer at $60{ }^{\circ} \mathrm{C}$ for $20 \mathrm{~min}$ followed by washes in $0 \cdot 2 \times \mathrm{SSC} / 0 \cdot 1 \% \mathrm{SDS}$ until background signals were barely detectable. The membrane was then subjected to autoradiography.

\section{Western blot}

Cultured cells were trypsinized and lysed in radioimmunoprecipitation assay buffer $\left(10 \mathrm{mmol} \mathrm{L}{ }^{-1}\right.$ Tris $\mathrm{pH} 7 \cdot 4,50 \mathrm{mmol} \mathrm{L}^{-1}$ $\mathrm{NaCl}, 1 \mathrm{mmol} \mathrm{L}{ }^{-1}$ EDTA, $10 \mathrm{mmol} \mathrm{L}^{-1} \mathrm{KCl}, 1 \%$ Nonidet P40, $0 \cdot 1 \%$ SDS and $0 \cdot 05 \%$ Tween 20) supplemented with protease inhibitors $\left[10 \mu \mathrm{g} \mathrm{mL}^{-1}\right.$ aprotinin, $10 \mu \mathrm{g} \mathrm{mL}^{-1}$ leupeptin and $1 \mathrm{mmol} \mathrm{L}{ }^{-1}$ phenylmethylsulphonyl fluoride (PMSF)]. Lysates were sonicated and then clarified by centrifugation at 14,500 r.p.m. at $4{ }^{\circ} \mathrm{C}$ for $15 \mathrm{~min}$. Protein concentrations were measured using the Bio-Rad protein assay kit (Bio-Rad, Hercules, CA, U.S.A.). Equal amounts (20-30 $\mu \mathrm{g})$ of samples were resolved under reducing conditions by $10 \%$ SDS-polyacrylamide gel electrophoresis (PAGE) and transferred on to polyvinylidene difluoride membranes (Hybond-P; Amersham Pharmacia). The membranes were incubated for $1 \mathrm{~h}$ at room temperature with 5\% non-fat dried milk in TBS-T $(20 \mathrm{mmol}$ $\mathrm{L}^{-1}$ Tris- $\mathrm{HCl} \mathrm{pH} \mathrm{7} \cdot 4,140 \mathrm{mmol} \mathrm{L}^{-1} \mathrm{NaCl}, 0 \cdot 1 \%$ Tween 20). After thoroughly washing in TBS-T, the membranes were incubated with anti-BRK $(1: 1000)$ or anti-Src (1 : 1000; Upstate, Lake Placid, NY, U.S.A.) antibodies diluted in $0 \cdot 1 \%$ BSA/TBS-T at $4{ }^{\circ} \mathrm{C}$ overnight. After washing, the membranes were incubated with HRP-conjugated antirabbit $(1: 8000)$ or antimouse (1: 5000) antibody for $1 \mathrm{~h}$ at room temperature. Specific bindings of the antibodies were visualized by the ECL detection system (Amersham Pharmacia). To monitor equal loading of proteins, membranes were stripped in buffer containing $100 \mathrm{mmol} \mathrm{L}^{-1} 2$-mercaptoethanol, 2\% SDS and $62.5 \mathrm{mmol} \mathrm{L}^{-1}$ Tris- $\mathrm{HCl}(\mathrm{pH} 6 \cdot 7)$ at $55{ }^{\circ} \mathrm{C}$ for $25 \mathrm{~min}$ and then incubated with anti $\alpha$-tubulin (1:4000) and antimouse (1:5000) secondary antibodies.

\section{In vitro kinase assay}

$\mathrm{HaCaT}$ cells were cultured in culture medium until $80 \%$ confluence, and then incubated overnight in low calcium medium. The medium was aspirated and the cells were washed with $\mathrm{PBS}$, and then $\mathrm{Ca} 2+\left(1.8 \mathrm{mmol} \mathrm{L}^{-1}\right)$ and ionomycin (10 $\mathrm{mol} \mathrm{L}^{-1}$; Sigma) were added for various durations. Cells were lysed in BRK lysis buffer $\left(50 \mathrm{mmol} \mathrm{L}^{-1}\right.$ HEPES $\mathrm{pH} 7 \cdot 4,150 \mathrm{mmol} \mathrm{L} \mathrm{L}^{-1} \mathrm{NaCl}, 5 \mathrm{mmol} \mathrm{L} \mathrm{L}^{-1} \mathrm{MgCl} 2$, $1 \mathrm{mmol} \mathrm{L}{ }^{-1}$ EGTA and $1 \%$ Triton X-100) ${ }^{15}$ supplemented with $10 \mu \mathrm{g} \mathrm{mL}^{-1}$ aprotinin, $10 \mu \mathrm{g} \mathrm{mL}^{-1}$ leupeptin, $1 \mathrm{mmol}$ $\mathrm{L}^{-1}$ PMSF, $1 \mathrm{mmol} \mathrm{L} \mathrm{L}^{-1} \mathrm{NaVO}_{3}, 4 \mathrm{mmol} \mathrm{L} \mathrm{L}^{-1} \mathrm{NaPPi}$ and $20 \mathrm{mmol} \mathrm{L}^{-1} \mathrm{NaF}$. Lysates were precleared with $15 \mu \mathrm{L}$ protein A sepharose beads (Amersham Pharmacia) at $4{ }^{\circ} \mathrm{C}$ for $1 \mathrm{~h}$. About $1 \mathrm{mg}$ of total cellular protein was incubated with $1 \mu \mathrm{g}$ of BRK antibody for $1.5 \mathrm{~h}$ and then $25 \mu \mathrm{L}$ protein A beads were added for another $1.5 \mathrm{~h}$. After washing three times with BRK lysis buffer, the complex was then washed twice with kinase buffer $\left(20 \mathrm{mmol} \mathrm{L}^{-1}\right.$ HEPES pH 7·4, $1 \mathrm{mmol} \mathrm{L}^{-1}$ dithiothreitol, $10 \mathrm{mmol} \mathrm{L}^{-1} \mathrm{MnCl} 2$ and $10 \mathrm{mmol} \mathrm{L}{ }^{-1} \mathrm{MgCl}_{2}$ ). The kinase reaction was carried out in kinase buffer supplemented with $10 \mu \mathrm{Ci}\left[\gamma_{-}{ }^{32} \mathrm{P}\right]$ ATP for $20 \mathrm{~min}$ at $30^{\circ} \mathrm{C}$, and terminated by the addition of SDS sample buffers. Proteins were resolved on SDS-PAGE and BRK autophosphorylation was detected by autoradiography.

\section{Semiquantatitive reverse transcription-polymerase chain reaction}

Cellular RNAs were isolated as described above. To eliminate genomic DNA contamination, RNA samples were treated with DNase I ( $1 \mathrm{U} \mu \mathrm{L}^{-1}$; Gibco-BRL) at room temperature for $15 \mathrm{~min}$, followed by the addition of $2 \mathrm{mmol} \mathrm{L}^{-1}$ EDTA and incubation at $70{ }^{\circ} \mathrm{C}$ for $10 \mathrm{~min}$ to inactivate DNase. Experimental parameters such as primers, RNA concentrations and PCR cycles were preliminarily adjusted to demonstrate linearity, allowing a reliable semiquantatitive analysis of signal strength. First-strand cDNA was synthesized from $5 \mu \mathrm{g}$ total RNA with 20 U RNAsin ribonuclease inhibitors (Promega, Madison, WI, U.S.A.), 200 University of Moloney murine leukaemia virus reverse transcriptase (Gibco-BRL), $0.5 \mu \mathrm{g} \mathrm{mL}^{-1}$ random primers (Promega) and $0.5 \mathrm{mmol} \mathrm{L}^{-1}$ deoxyribonucleoside triphosphate (dNTP) incubated at $37{ }^{\circ} \mathrm{C}$ for $4 \mathrm{~h}$. After reverse transcription, PCR amplification was performed using Taq DNA polymerase (Protech, Taipei, Taiwan) and dNTP under the following conditions: 29 cycles of denaturing at $95{ }^{\circ} \mathrm{C}$ for $1 \mathrm{~min}$, annealing at $50{ }^{\circ} \mathrm{C}$ for $1 \mathrm{~min}$ and extension at $72{ }^{\circ} \mathrm{C}$ for $2 \mathrm{~min}$. Final extension was at $72{ }^{\circ} \mathrm{C}$ for $5 \mathrm{~min}$, and the reaction was terminated at $4{ }^{\circ} \mathrm{C}$. PCR products were electrophoresed in a $2 \%$ agarose gel and visualized using ethidium bromide. To control for quality of RNA and reverse transcription, reactions for, $\beta$-actin were performed in parallel. The primers used were: K10 forward sequence ACT ACA AAA CCA TCG ATG AC, K10 reverse 
sequence GCA AGT TGT TCA TAT TGG CT; $\beta$-actin forward sequence ATA GGA ATC CTT CTG ACC CA, and, $\beta$-actin reverse sequence ATG GAT GAT GAT ATC GC.

\section{Results}

\section{Breast tumour kinase is distributed in suprabasal keratinocytes of the epidermis}

In all normal skin specimens examined, BRK was found exclusively in the suprabasal epidermal cells (Fig. 1A,B). It was barely detectable in the basal layer, and significantly increased in the differentiated layers. The subcellular localization of BRK was mainly in the cytoplasm. The pattern became homogeneous and very intense throughout the cells within the upper Malpighian layer (Fig. 1B). The hair root sheath was devoid of BRK expression (Fig. 1A). All the retrieved skin tumours, including follicular (e.g. trichoepithelioma, trichoblastoma), neural (e.g. neurofibroma, neuroma) and sweat gland-derived (e.g. syringoma, eccrine poroma) benign tumours as well as basal cell carcinoma, melanoma and extramammary Paget's disease, showed negative staining results (data not shown), except for squamous cell carcinoma (SCC), where some positive staining areas were detected in the keratinized horn pearls or small cell groups, but not in the atypical cells (Fig. 1C). The horn pearls represent the more differentiated regions in the tumours and are absent in poorly differentiated SCC. ${ }^{16}$

The pattern of BRK expression in the epidermis suggested an association with keratinocyte differention. We subsequently went on to cell culture systems where the differentiation process could be easily manipulated in vitro. In comparison with several breast tumour cell lines reported to contain high levels of BRK protein, ${ }^{17} \mathrm{HaCaT}$ cells also exhibited abundant BRK expression (Fig. 2). Because of their ease of manipulation and physiological characteristics comparable with those of primary human keratinocytes, ${ }^{12,13}$ HaCaT cells represent a suitable model for our experimental purpose.

\section{Breast tumour kinase exhibits an enhanced expression pattern during $\mathrm{HaCaT}$ cell differentiation}

As cultured HaCaT cells attain confluence, they cease proliferation and begin to differentiate. ${ }^{18}$ Confluence is thus a frequently used model for in vitro differentiation of $\mathrm{HaCaT}$ cells, and avoids the addition of exogenous stimuli or chemicals, which may influence the observed phenotype. ${ }^{19}$ With this system, we observed by immunofluorescence staining a higher number of cells expressing $\mathrm{K} 10$ in the confluent regions than in subconfluent areas (Fig. 3A). Consistent with a previous study, ${ }^{13}$ confluence led to an increasing number of strongly stained cells rather than a gradual up-regulation in all cells. We next examined the subcellular localization of BRK and compared its distribution pattern with that of differentiation markers. For subconfluent cells, BRK was uniformly distributed in the nucleus and cytoplasm, being much stronger in the former location (Fig. 3B,a-c). A significant enhancement

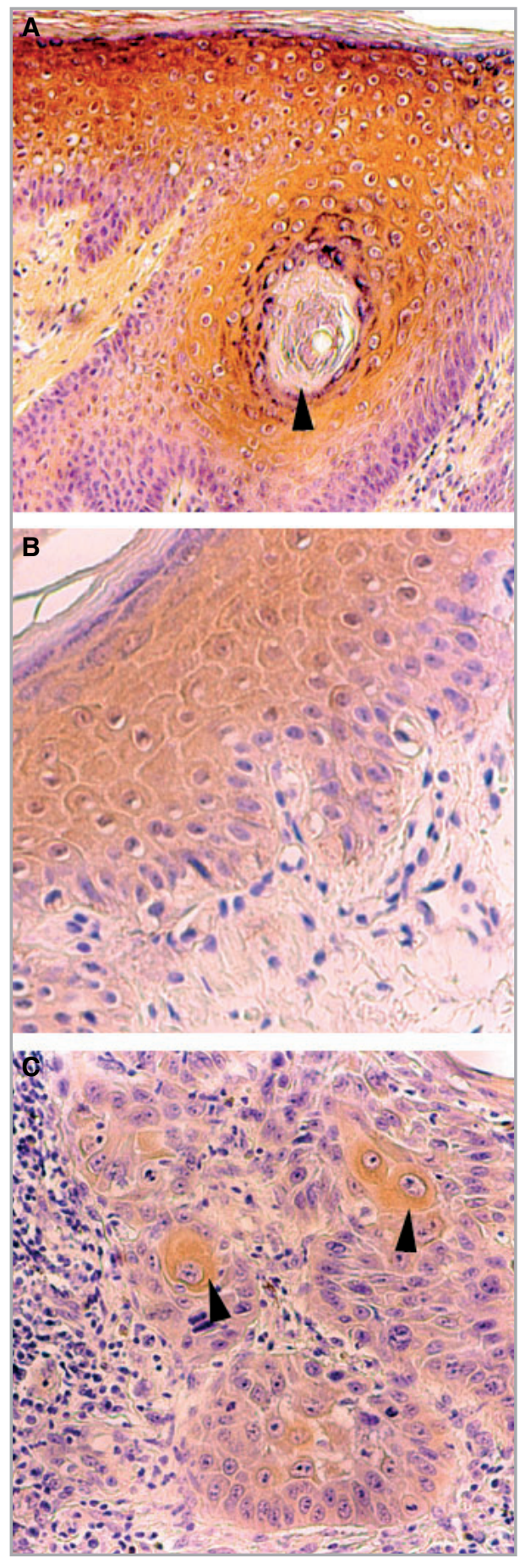

Fig 1. Immunohistochemical staining for breast tumour kinase (BRK) in skin. (A) The distribution is suprabasal, and BRK is mainly found in the cytoplasm. The hair root sheath is devoid of BRK expression (arrowhead). (B) Close-up view of epidermal BRK distribution. A homogeneous, nuclear and cytoplasmic pattern is seen in the upper cells. (C) Squamous cell carcinoma (SCC). BRK is distributed only in the suprabasal epidermal keratinocytes and focal keratinized cells of SCC (arrowheads). Original magnification: $(A) \times 40$ (B,C) $\times 200$.

of BRK staining was observed in certain areas of the more confluent culture (Fig. 3B,d-f), akin to the K10 pattern described above. However, results of double immunostaining did 


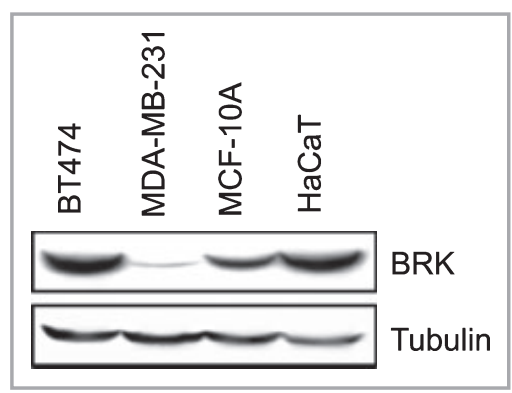

Fig 2. Breast tumour kinase (BRK) expression in various cell lines. Lysates were prepared from breast carcinoma cell lines BT-474 and MDA-MB-231, breast epithelial cell line MCF-10 A and HaCaT cells for Western blot analysis with anti-BRK antibody. The membrane was stripped and hybridized with tubulin for normalization.

not show coinduction of BRK and K10 in the same cell, indicating that the two proteins are regulated in a spatially and/or temporally distinct manner (Fig. 3C,a-d).

\section{Serum-dependent up-regulation of breast tumour kinase during differentiation of $\mathrm{HaCaT}$ cells}

Quantitative changes in BRK expression during keratinocyte differentiation were also investigated. BRK mRNA and protein were significantly up-regulated in overconfluent cells cultured in regular culture medium (Fig. 4). Before reaching confluence, BRK expression remained stationary (data not shown), indicating that the up-regulation is not merely a function of time in culture. However, this up-regulation of BRK was significantly blocked in cells cultured in serum-free medium, demonstrating a requirement for serum factors for this up-regulation. Notably, the structurally related Src, which also shows certain features pertinent to keratinocyte differentiation, ${ }^{20,21}$ did not show down-regulation to a similar extent in serum-free conditions (Fig. 4B), indicating that the serumfree effect is not universal.

\section{Calcium/ionomycin stimulates the kinase activity of breast tumour kinase}

Primary keratinocytes can be induced to differentiate in vitro by elevation of the calcium concentration in the culture medium, ${ }^{4}$ in the meantime accompanied by increased cellular protein tyrosine phosphorylation. ${ }^{1}$ Sik, the mouse homologue of BRK, can be rapidly activated by the addition of calcium and represents an early kinase activated during keratinocyte differentiation. ${ }^{11}$ We therefore determined whether BRK could be similarly regulated, as data obtained from mice might not be applicable to humans.

As increasing extracellular calcium concentration alone induces only early signs of differentiation but not terminal differentiation, ${ }^{18}$ a calcium ionophore, ionomycin, is needed to act together with calcium ions to bring about terminal differentiation. $^{20}$ The kinase activity of BRK in HaCaT cells treated with calcium/ionomycin was examined by an in vitro
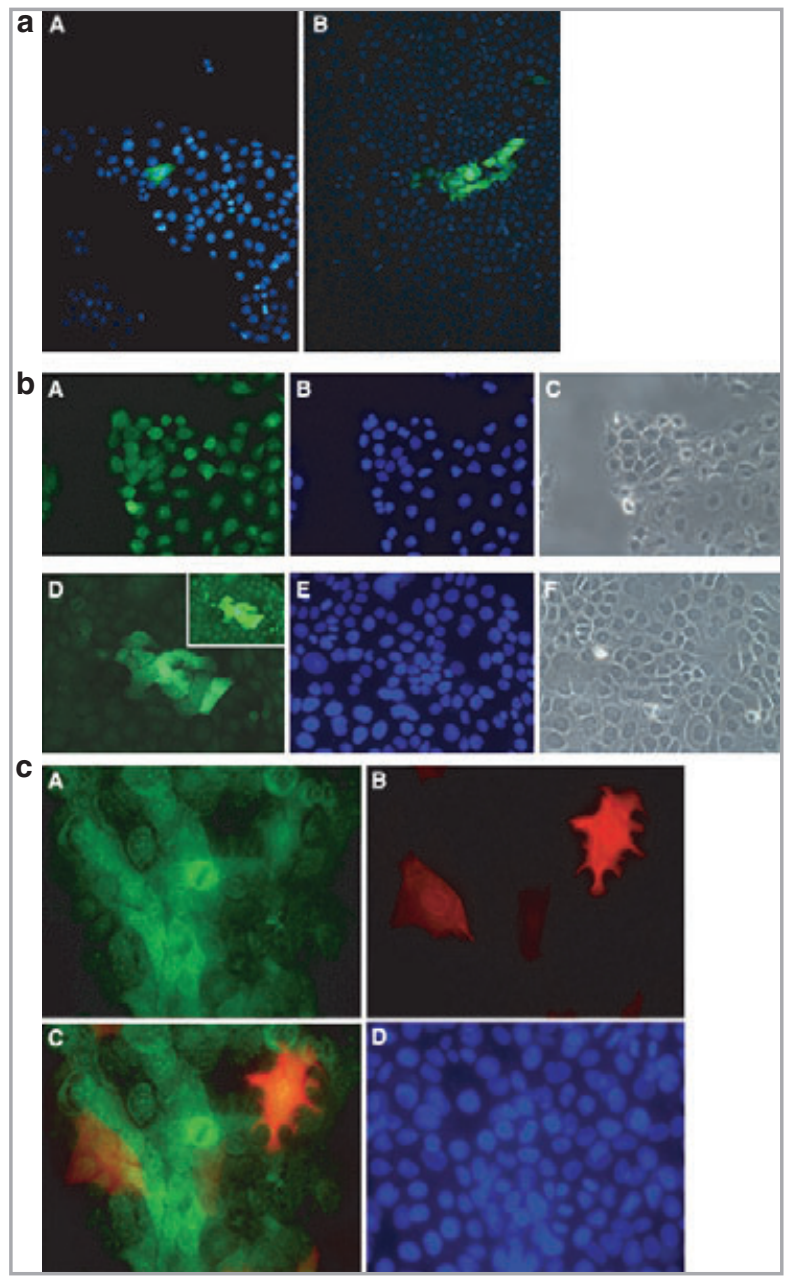

Fig 3. Differentiation-induced expression of breast tumour kinase (BRK) and keratin 10 (K10). (A) Confluence induces differentiation of $\mathrm{HaCaT}$ cells. Indirect immunofluorescence staining of $\mathrm{HaCaT}$ cells with K10 antibody superimposed on Hoechst 33258 nuclear image:

(a) subconfluence; (b) confluence. (B) Confluence up-regulates BRK expression. At low cell density $(\mathrm{a}-\mathrm{c})$, the expression of BRK is evenly distributed, with a stronger nuclear localization. At high density $(\mathrm{d}-\mathrm{f})$, cells are confluent, densely packed, and an enhanced expression of BRK can be detected (d, central area). When image d was exposed at a time period as in image a (inset), BRK expression was evident in background cells. (a,d) BRK, green; (b,e) Hoechst 33258; (c,f) phase contrast). (C) Double immunostaining of BRK and K10. Cells were cultured until confluence, and double immunostaining of BRK (a, green) and K10 (b, red) was performed. (c) Merging of A and B did not show a close spatial correlation between BRK and K10. (d) Hoechst 33258 nuclear staining.

kinase assay with histone $2 \mathrm{~B}$ as an exogenous substrate (Fig. 5). Similar to Sik, BRK catalytic activity was quickly activated within $5 \mathrm{~min}$ after the addition of calcium and ionomycin, as determined both by histone $2 \mathrm{~B}$ phosphorylation and by BRK autophosphorylation. However, in contrast to Sik, whose activity persists for $24 \mathrm{~h}$, the kinase activity of BRK returned to the basal level at $30 \mathrm{~min}$ after treatment. Western blot analysis showed an equal amount of BRK 


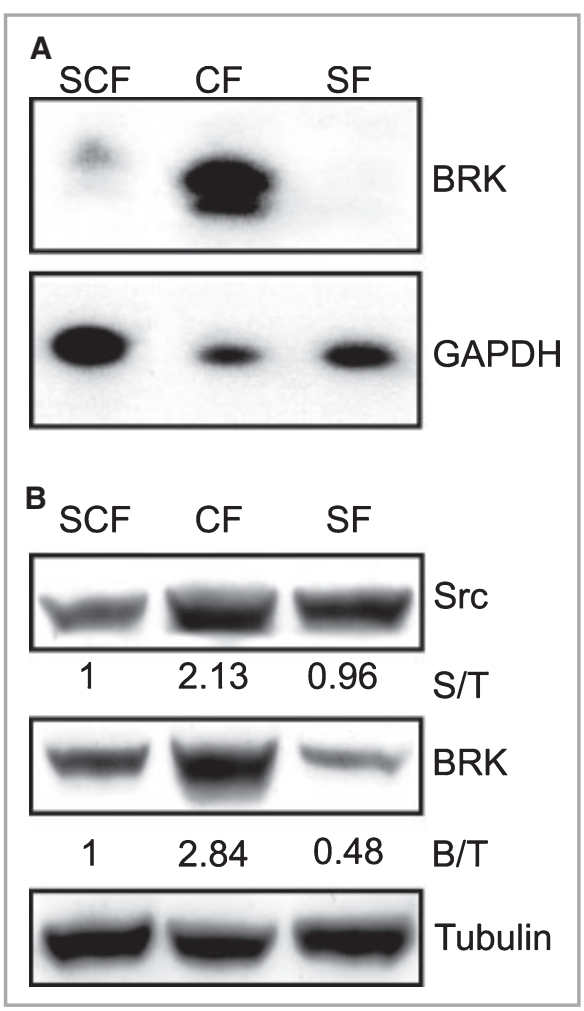

Fig 4. Serum-dependent, confluence-induced up-regulation of breast tumour kinase (BRK). HaCaT cells were cultured in Dulbecco's modified Eagle's medium $/ 10 \%$ fetal calf serum for 3 days (subconfluence, SCF). As cells reached confluence, they were cultured in original medium (CF) or serum-free medium (SF) for a total of 11 days. (A) Northern blot analysis demonstrating the expression of BRK mRNA in various groups as indicated. GAPDH, glyceraldehyde3-phosphate. (B) Western blot analysis demonstrating the expression of BRK and Src proteins in various groups. Respective densitometry ratios of Src to tubulin $(\mathrm{S} / \mathrm{T})$ and $\mathrm{BRK}$ to tubulin $(\mathrm{B} / \mathrm{T})$ are shown at the bottom of each lane.

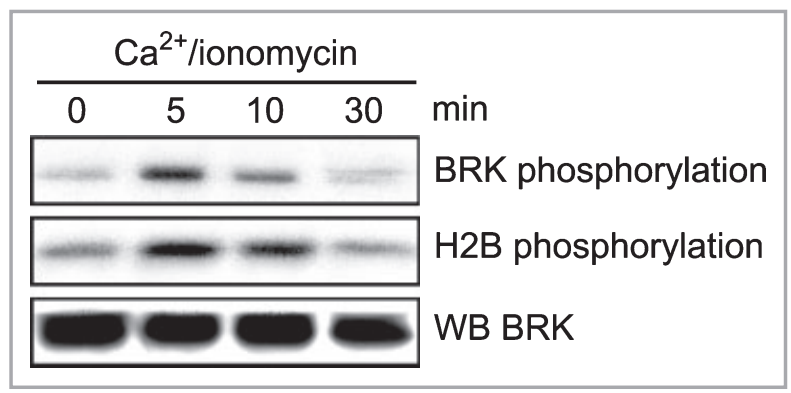

Fig 5. Influence of calcium on the kinase activity of breast tumour kinase (BRK). Cells were treated with calcium and ionomycin for the times indicated. Lysates were immunoprecipitated with BRK antibodies, and an in vitro kinase assay was performed in the presence of histone 2B (H2B). Reactions were analysed by autoradiography. BRK autophosphorylation and $\mathrm{H} 2 \mathrm{~B}$ phosphorylation are shown in the upper and middle panels, respectively. The membrane was reprobed with BRK antibody for normalization. WB, Western blot.

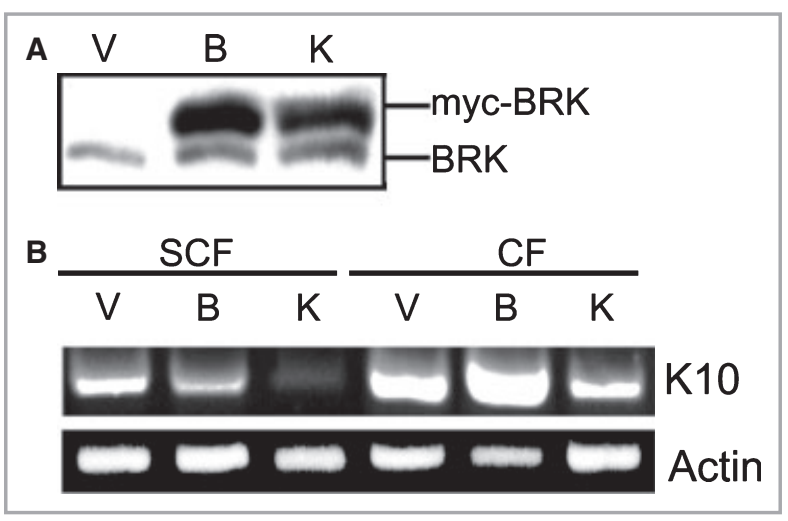

Fig 6. Influence of breast tumour kinase (BRK) on the expression of differentiation markers. (A) Western blot revealed the presence of endogenous and Myc-tagged BRK, confirming the presence of transfected genes from respective stable $\mathrm{HaCaT}$ cell lines. V, vector; $\mathrm{B}$, BRK; K, kinase-defective mutant K219M. (B) Semiquantitative reverse transcription-polymerase chain reaction analyses of cells either in subconfluent (3 days after seeding: SCF) or in postconfluent (7 days after seeding: CF) cultures. Keratin 10 (K10) transcripts were moderately up-regulated in the BRK groups; but were significantly suppressed in the $\mathrm{K} 219 \mathrm{M}$ group.

immunoprecipitated at each time point, indicating that the variations were not a result of changes in amounts of protein.

\section{Overexpression of breast tumour kinase (BRK) and kinase-defective BRK mutant affects differentiation of HaCaT cells}

To investigate the effects of BRK on keratinocyte differentiation further, we determined the role of BRK in the expression of the early differentiation marker K10. HaCaT cells stably expressing vector control, wild-type BRK or its kinase-defective mutant (K219M) were generated via retrovirus-mediated gene transfer, and Western blot analysis demonstrated the expression of wildtype or mutant BRK in respective cells (Fig. 6A). The K219M mutant was able to block the activity and biological functions of the endogenous BRK, and thus functions as a dominant-negative mutant. ${ }^{22}$ We found that as cells reached postconfluence, K10 mRNA was up-regulated more in cells overexpressing BRK than in the vector cells; however, in cells overexpressing K219M, K10 was significantly suppressed, although there was still some up-regulation as cells became differentiated (Fig. 6B). These results indicate a functional role of $\mathrm{BRK}$ in differentiation of HaCaT cells.

\section{Discussion}

Previous studies reveal a dual role of BRK in tumour formation and epithelial cell differentiation. The oncogenic role of BRK is supported by its enhanced expression in some tumours, ${ }^{6-8,17}$ and the underlying mechanisms can be partly attributed to activation of the EGF-phosphoinositide 3 kinaseAkt pathway ${ }^{15}$ and phosphorylation of paxillin ${ }^{22}$ and 
Sam $68 .^{23}$ However, the mechanisms of its role in regulation of differentiation are less well understood. The mouse orthologue Sik is activated early during keratinocyte differentiation and promotes filaggrin expression upon overexpression. ${ }^{11}$ The subcellular distribution and kinase activity of BRK are altered in poorly differentiated prostate tumour cells, suggesting a role in differentiation of prostate epithelial cells. ${ }^{8}$

The ubiquitous expression of BRK in skin provides good opportunities to study its roles in cutaneous biology. Our histochemical analyses demonstrated that BRK is distributed exclusively in the suprabasal layers of the epidermis, and it was not present in various benign or malignant skin tumours. In the SCC specimens, BRK was present only in the well differentiated regions. Whether loss of BRK expression in the less differentiated areas is a cause or a consequence of cell transformation is not known, but loss of normal expression of tyrosine kinases such as Sky24 and c-KIT25 in breast tumours and PTK7 and Sek in metastatic melanomas ${ }^{7}$ have been reported to play a role in carcinogenesis.

Our indirect immunofluorescence results demonstrated that as cells reached confluence, some of the suprabasal keratinocytes expressed BRK more strongly than did the background basal cells, supporting the in vivo data and indicating up-regulation of BRK during keratinocyte differentiation. Despite lacking a nuclear localization signal, ${ }^{23}$ we found that the intracellular distribution of BRK was both cytoplasmic and nuclear in $\mathrm{HaCaT}$ cells. There was no obvious spatial correlation between BRK and K10, suggesting that they relate to different stages or mechanisms of differentiation. Lack of coexpression of differentiation markers has also been reported for the $\mathrm{K} 10 /$ involucrin $^{2}$ and $\mathrm{K} 1 / \mathrm{K} 10^{13}$ pairs. Furthermore, the unsynchronized expression and different locations of $\mathrm{K} 1$ and $\mathrm{K} 10$ positive cells have led to a hypothesis that the expression of K1 may create conditions for K10 synthesis. ${ }^{13}$ We noted that prominent BRK-expressing cells were largely arranged in clusters and were located immediately suprabasally, while K10expressing cells were more individually distributed and were confined to a higher layer. By analogy, we speculate that during the differentiation process, BRK might be involved in earlier events and in preparation for the entry of cells into the phenotypically differentiated stage.

Another observation in this study is the elevated expression of BRK with keratinocyte differentiation. A similar up-regulation of BRK during differentiation was reported for the human colon carcinoma cell line Caco-2, which differentiates spontaneously after confluence. ${ }^{6}$ However, the peak protein expression in Caco-2 cells was 7 days after plating, ${ }^{6}$ while in $\mathrm{HaCaT}$ cells the up-regulation of BRK protein could persist for 21 days after plating (data not shown). In the context of different turnover rates between epithelia of the intestinal tract and of the skin, BRK may be regulated differently in these two cell lines. Although the underlying mechanism for this differentiation-induced BRK expression is currently unclear, our study reveals a requirement of serum factors for this effect. Further studies are needed to determine which serum factor(s) are responsible for this regulation of BRK.
Although cell confluence is a physiological stimulus for keratinocyte differentiation, ${ }^{26}$ it is difficult to distinguish differentiated and undifferentiated states by confluence alone. In contrast, an increase in extracellular calcium concentration can induce early signs of differentiation ${ }^{18}$ and provides a specific signal. Similar to Sik, ${ }^{11}$ BRK can be rapidly activated in response to calcium and ionophores, although BRK activation occurs more transiently than that of Sik. Because calcium influx is sufficient to transactivate the EGF receptor (EGFR), ${ }^{27}$ and EGF signalling similarly induces a transient activation of BRK, ${ }^{22}$ it is plausible that calcium activates BRK through an EGFR-dependent mechanism.

We showed that transfection of wild-type BRK moderately enhanced while the dominant-negative BRK profoundly inhibited the expression of $\mathrm{K} 10$, implying that its kinase activity is involved in regulating keratinocyte differentiation. In addition to being involved in maintaining the integrity of cellular architecture, overexpression of $\mathrm{K} 10$ in $\mathrm{HaCaT}$ cells inhibits the proliferation of cells via the retinoblastoma pathway, ${ }^{28}$ indicating a functional significance for K10. However, based on our results and the published data, ${ }^{29}$ postconfluent $\mathrm{HaCaT}$ cells in serum-free condition can still express K10, while they lose the ability to express BRK, indicating that K10 expression is not associated with that of BRK. These data argue against an indispensable role for BRK in keratinocyte differentiation, and perhaps other structurally and functionally related kinases play a redundant function with BRK.

To sum, the suprabasal distribution, its early activation by calcium/ionomycin, and influence on K10 expression all demonstrate that BRK plays a role in early steps of keratinocyte differentiation. In addition to uncover the cellular targets and functions, it will be informative to study the activity or distribution of BRK in various skin diseases that show hyperproliferation or aberrant differentiation, such as psoriasis or various keratodermas.

\section{Acknowledgment}

T.C.W. and S.H.J. contributed equally to this work. This work was supported by NSC Frontier Grant NSC93-2321-B-002017 .

\section{References}

1 Filvaroff E, Stern DF, Dotto GP. Tyrosine phosphorylation is an early and specific event involved in primary keratinocyte differentiation. Mol Cell Biol 1990; 10:1164-73.

2 Paramio JM, Jorcano JL. Role of protein kinases in the in vitro differentiation of human epidermal HaCaT cells. Br J Dermatol 1997; 137:44-50.

3 Calautti E, Missero P, Stein PL et al. Fyn tyrosine kinase is involved in keratinocyte differentiation control. Genes Dev 1995; 9:2279-91.

4 Dotto GP. Signal transduction pathways controlling the switch between keratinocyte growth and differentiation. Crit Rev Oral Biol Med 1999; 10:442-57.

5 Mitchell PJ, Barker KT, Martindale JE et al. Cloning and characterisation of cDNAs encoding a novel non-receptor tyrosine kinase, 
brk, expressed in human breast tumours. Oncogene 1994; 9:238390 .

6 Llor X, Serfas MS, Bie W et al. BRK/Sik expression in the gastrointestinal tract and in colon tumours. Clin Cancer Res 1999; 5:1767-77.

7 Easty DJ, Mitchell PJ, Patel $\mathrm{K}$ et al. Loss of expression of receptor tyrosine kinase family genes PTK7 and SEK in metastatic melanoma. Int J Cancer 1997; 71:1061-5.

8 Derry JJ, Prins GS, Ray V, Tyner AL. Altered localization and activity of the intracellular tyrosine kinase BRK/Sik in prostate tumour cells. Oncogene 2003; 22:4212-20.

9 Harvey AJ, Crompton MR. Use of RNA interference to validate Brk as a novel therapeutic target in breast cancer: Brk promotes breast carcinoma cell proliferation. Oncogene 2003; 22:5006-10.

10 Vasioukhin V, Serfas MS, Siyanova EY et al. A novel intracellular epithelial cell tyrosine kinase is expressed in the skin and gastrointestinal tract. Oncogene 1995; 10:349-57.

11 Vasioukhin V, Tyner AL. A role for the epithelial-cell-specific tyrosine kinase Sik during keratinocyte differentiation. Proc Natl Acad Sci USA 1997; 94:14477-82.

12 Boukamp P, Petrussevska RT, Breitkreutz D et al. Normal keratinization in a spontaneously immortalized aneuploid human keratinocyte cell line. J Cell Biol 1988; 106:761-71.

13 Ryle CM, Breitkerutz D, Stark HJ et al. Density-dependent modulation of synthesis of keratins 1 and 10 in the human keratinocyte line HACAT and in ras-transfected tumorigenic clones. Differentiation 1989; 40:42-54.

14 Kamalati T, Jolin HE, Mitchell PJ et al. Brk, a breast tumor-derived non-receptor protein-tyrosine kinase, sensitizes mammary epithelial cells to epidermal growth factor. J Biol Chem 1996; 271:3095663.

15 Kalamati T, Jolin HE, Fry MJ, Crompton MR. Expression of the BRK tyrosine kinase in mammary epithelial cells enhances the coupling of EGF signaling to PI 3-kinase and Akt, via erbB3 phosphorylation. Oncogene 2000; 19:5471-6.

16 Kirkham N. Tumors and cysts of the epidermis. In: Lever's Histopathology of the Skin (Elder D, Elenitsas R, Jaworsky C, Johnson B Jr, eds.), 8th edn. Philadelphia: Lippincott-Raven, 1997: 712-5.

17 Barker KT, Jackson LE, Crompton MR. BRK tyrosine kinase expression in a high proportion of human breast carcinomas. Oncogene 1997; 15:799-805.
18 Rogers MS, Kobayashi T, Pittelkow MR, Strehler EE. Human calmodulin-like protein is an epithelial-specific protein regulated during keratinocyte differentiation. Exp Cell Res 2001; 267:216-24.

19 Grabbe J, Welker P, Rosenbach $\mathrm{T}$ et al. Release of stem cell factor from a human keratinocyte line, $\mathrm{HaCaT}$, is increased in differentiating versus proliferating cells. J Invest Dermatol 1996; 107:219-24.

20 Zhao Y, Sudol M, Hanafusa H, Krueger J. Increased tyrosine kinase activity of $\mathrm{c}$-Src during calcium-induced keratinocyte differentiation. Proc Natl Acad Sci USA 1992; 89:8298-302.

21 Jin F, Reynolds $A B$, Hines $M D$ et al. Src induces morphological changes in A431 cells that resemble epidermal differentiation through an SH3- and Ras-independent pathway. J Cell Sci 1999; 112:2913-24.

22 Chen HY, Shen CH, Tsai YT et al. Brk activates Rac1 and promotes cell migration and invasion by phosphorylating paxillin. Mol Cell Biol 2004; 24:10558-72.

23 Derry JJ, Richard S, Carvajal HV et al. Sik (BRK) phosphorylates Sam68 in the nucleus and negatively regulates its RNA binding ability. Mol Cell Biol 2000; 20:6114-26.

24 Coopman PJ, Do MT, Barth M et al. The syk tyrosine kinase suppresses malignant growth of human breast cancer cells. Nature 2000; 406:742-7.

25 Chui X, Egami H, Yamashita J et al. Immunohistochemical expression of the breast tissues. Br J Cancer 1996; 73:1233-6.

26 Poumay Y, Pittelkow M. Cell density and culture factors regulate keratinocyte commitment to differentiation and expression of suprabasal K1/K10 keratins. J Invest Dermatol 1995; 104:271-6.

27 Prenzel N, Zwick E, Leserer M, Ullrich A. Tyrosine kinase signaling in breast cancer epidermal growth factor receptor: convergence point for signal integration and diversification. Breast Cancer Res 2000; 2:184-90.

28 Paramio JM, Casanova ML, Segrelles C et al. Modulation of cell proliferation by cytokeratins K10 and K16. Mol Cell Biol 1999; 19:3086-94.

29 Paramio JM, Lain S, Segrelles C et al. Differential expression and functionally co-operative roles of the retinoblastoma family of proteins in epidermal differentiation. Oncogene 1998; 17:949-57. 